\title{
Protective effects of the SEPS1 gene on lipopolysaccharide-induced sepsis
}

\author{
LEI HE $^{1 *}$, BIN WANG $^{2^{*}}$, YUAN YAO $^{3^{*}}$, MAOSHENG SU $^{1}$, HUANXIAN MA $^{1}$ and NING JIA ${ }^{4}$ \\ Departments of ${ }^{1}$ Hepatobiliary Surgery, ${ }^{2}$ Critical Care Medicine, ${ }^{3}$ Medical Quality Control and \\ ${ }^{4}$ Nosocomial Infection and Disease Control, PLA General Hospital, Beijing 100853, P.R. China
}

Received May 31, 2013; Accepted January 28, 2014

DOI: $10.3892 / \mathrm{mmr} .2014 .1991$

\begin{abstract}
Septic shock and sequential multiple organ failure are the main cause of mortality in patients with sepsis. The induction of inflammation during sepsis is a complex biological cascade, which requires successful therapeutic intervention. Selenoprotein S (SEPS1) is a novel endoplasmic reticulum-resident protein and is important in the production of inflammatory cytokines. The present study attempted to assess the effect of SEPS1 suppression by small interfering RNA (siRNA) on mice with lipopolysaccharide (LPS)-induced sepsis. In total, 30 mice were randomly assigned to three groups: i) H group (LPS-induced sepsis group; $n=10)$ : Mice with intraperitoneal injection of LPS (10 mg/kg); ii) K group (scrambled siRNA group; $\mathrm{n}=10$ ): Mice transfected with scrambled control siRNA $12 \mathrm{~h}$ prior to injection with LPS and iii) L group (SEPS1 siRNA group; $\mathrm{n}=10$ ): Mice transfected with SEPS1 siRNA $12 \mathrm{~h}$ prior to injection with LPS. The effects of siRNA were evaluated by SEPS1 gene and protein expression, biochemical parameters including serum alanine transaminase (ALT), aspartate aminotransferase (AST), blood urea nitrogen (BUN), lactic dehydrogenase $(\mathrm{LDH})$, creatine kinase $(\mathrm{CK})$ and myocardial kinase (CK-MB), as well as the cytokines interleukin-6 (IL-6) and tumor necrosis factor- $\alpha(\mathrm{TNF}-\alpha)$. The phosphorylation of p38 mitogen-activated protein kinases (p38 MAPK) was also detected by western blot analysis. In the SEPS1 siRNA group, SEPS1 gene and protein expression decreased significantly, while the levels of TNF- $\alpha$ and IL- 6 increased compared with the control group. The biochemical parameters of ALT, AST, BUN, LDH, CK and CK-MB were markedly increased in the SEPS1 siRNA group. The phosphorylation of p38 MAPK was
\end{abstract}

Correspondence to: Mrs. Ning Jia, Department of Nosocomial Infection and Disease Control, PLA General Hospital, No. 28 Fuxing Road, Haidian, Beijing 100853, P.R. China

E-mail: jianing@263.net

*Contributed equally

Key words: selenoprotein $\mathrm{S}$, sepsis, small interfering RNA, protective effect also significantly activated. The decrease in SEPS1 gene and protein expression and the production of TNF- $\alpha$ and IL-6 may correlate with the activation of the p38 MAPK pathway. Biochemical factors and pathological results demonstrated that the damage to vital organs was aggravated. In conclusion, these findings suggested that SEPS1 may protect mice against LPS-induced sepsis and organ damage. Therefore, SEPS1 may be a new target to resolve LPS-induced sepsis.

\section{Introduction}

Immune system activation is involved in the pathogenesis of numerous common complex diseases, including cardiovascular disease, diabetes and cancer (1). Ongoing inflammatory insults may contribute to the development of such diseases. Inflammatory activation, a result of cellular exposure to stress conditions, is reflected by increases in levels of circulating proinflammatory cytokines (2). Sepsis is an increasingly common cause of morbidity and mortality, particularly in elderly, immunocompromised and critically ill patients (3). The most common cause of sepsis is an exposure to the structural component of a gram-negative bacterial membrane lipopolysaccharide (LPS), with key symptoms including hypotension and vasoplegia, which may lead to multiple organ dysfunction and, ultimately, mortality (4-6). Bacterial LPS in the bloodstream induces the overexpression of various inflammatory mediators, including interleukin-1 (IL-1), tumor necrosis factor- $\alpha$ (TNF- $\alpha$ ), and a large quantity of inflammatory mediators produced in the body are hypothesized to contribute to the LPS-induced symptoms of septic shock and mortality (7).

Selenoprotein S1 (SEPS1) has previously been identified as an endoplasmic reticulum stress response protein that is likely to correlate with an inflammatory response (8-10). Genetic variation in the SEPS1 gene was observed to correlate with circulating levels of pro-inflammatory cytokines in human populations and SEPS1 may regulate cytokine production in cultured macrophage cells $(11,12)$. The protective effect of SEPS1 on mice with sepsis is unknown. In order to investigate the role of SEPS1 in mice with sepsis, a LPS-induced sepsis model was used in the present study. SEPS1 small interfering RNA (siRNA) was used to silence the SEPS1 gene. The associated biochemical indicators as well as gene and protein expression were examined. 
Table I. Primer sequences of SEPS1 and scrambles.

Primer name

Primer sequence 5'-3'

SEPS1 antisense

SEPS1 sense

Scrambled antisense

Scrambled sense
AAGATCTAAATGCCCAAGTTGCCTGTCTC AACAACTTGGGCATTTAGATCCCTGTCTC AAGTATCTAGGTACACACTCACCTGTCTC AATGAGTGTACCTAGATACCCTGTCTC

SEPS1, selenoprotein S.

\section{Materials and methods}

Reagents. SEPS1, p38 mitogen-activated protein kinase (p38 MAPK), phosphorylated p38 mitogen-activated protein kinase (p-p38 MAPK) and $\beta$-actin antibodies were obtained from Santa Cruz Biotechnology, Inc. (Santa Cruz, CA, USA). Oligonucleotide primers and dNTP mix were purchased from Bio Basic Inc. (Bio Basic, Toronto, Canada). Protein extraction and BCA protein assay kits were purchased from Promega Co. (Madison, WI, USA). Pyrogen-free water was purchased from Shanghai Yihua Clinical Medicine Technologies Company (Shanghai, China). LPS (from E. coli strain O55:B5) and all other chemicals were purchased from Sigma-Aldrich (St. Louis, MO, USA).

Animals. Inbred BALB/c mice (male, 17-20 g), were purchased from the Institute of Medical Animal Experimental Center, Peking Union Medical College (Beijing, China). The mice were kept at standard laboratory conditions of temperature and humidity with a 12-h light/dark cycle. All experiments were performed according to the Guide for the Care and Use of Laboratory Animals (Institute of Laboratory Animal Resources, 1996) and were treated ethically. The study was approved by the Ethics Committee of PLA General Hospital (Beijing, China).

Animal transfection. siRNAs for SEPS1 and the scrambled control were synthesized in vitro using a kit from Ambion (Austin, TX, USA; Silencer ${ }^{\circledR}$ Negative Control No. 1 siRNA). Primer sequences are provided in Table I (Beijing AuGCT DNA-SYN Biotechnology Co., Ltd., Beijing, China). The mice were transfected with siRNA oligonucleotides $(0.5 \mu \mathrm{g})$ formulated by Lipofector 2000 (Beyotime Institute of Biotechnology, Jiangsu, China) via tail vein injection. In total, 30 mice were randomly assigned to three groups: i) $\mathrm{H}$ group (LPS-induced sepsis group; $\mathrm{n}=10$ ): Mice with intraperitoneal injection of LPS (10 mg/kg); ii) K group (scrambled siRNA group; $\mathrm{n}=10$ ): Mice transfected with scrambled control siRNA $12 \mathrm{~h}$ prior to injection with LPS; iii) L group (SEPS1 siRNA group; $\mathrm{n}=10$ ): Mice transfected with SEPS1 siRNA $12 \mathrm{~h}$ prior to injection with LPS. The mice in all groups fasted with free access to water following LPS injection and were continuously monitored over a 24 -h period. For each time-point (12 and $24 \mathrm{~h}$ ), five animals were used.

Assessment of blood biochemical parameters. Following the LPS injections at 12 and $24 \mathrm{~h}$, the blood was collected in heparinized tubes by extirpating the left eyeball of five mice in each group. Serum was isolated by centrifugation at $4,000 \mathrm{x} \mathrm{g}$, $4^{\circ} \mathrm{C}$ for $15 \mathrm{~min}$ and maintained at $-70^{\circ} \mathrm{C}$ until it was required for further analysis. The levels of serum alanine transaminase (ALT), aspartate aminotransferase (AST), serum creatinine (Cr), blood urea nitrogen (BUN), myocardial kinase (CK-MB), creatine kinase $(\mathrm{CK})$ and lactic dehydrogenase (LDH) were assessed using an automatic biochemical analyzer (HITACHI 7170, Hitachi, Ltd., Tokyo, Japan) with commercial kits (LDH-Cytotoxicity Assay Kit II; Biosino Biotechnology Co., Ltd., Beijing, China).

Assessment of TNF- $\alpha$ and IL- 6 in the liver homogenate. At each time-point of assessment, the mice were sacrificed once the blood had been obtained. Under strict aseptic conditions, 0.1-0.2 g of liver tissue was removed and placed into a pyrogen-free homogenizer. Three volume equivalents of pyrogen-free saline was added and the liver tissue was homogenized in an ice bath. The liver homogenate supernatant was prepared by centrifugation at $10,000 \mathrm{xg}$ at $4^{\circ} \mathrm{C}$ for $15 \mathrm{~min}$ and maintained at $-30^{\circ} \mathrm{C}$ until it was required for further analysis. The samples were analyzed for TNF- $\alpha$ and IL- 6 using an ELISA kit (Endogen Inc., Woburn, MA, USA) according to the manufacturer's instructions. The absorbance was measured at $450 \mathrm{~nm}$. The concentrations of TNF- $\alpha$ and IL- 6 in the experimental samples were extrapolated from a standard curve.

Western blot analysis. Once the mice had been sacrificed, the liver tissue samples were maintained in liquid nitrogen for western blot analysis. The liver tissue samples were cut up and ground with pre-cooled lysis buffer. Equal quantities of protein were separated by SDS-PAGE (10\% gel) and transferred to nitrocellulose (CN) membranes (Hybond Inc., Escondido, CA, USA). The membranes were blocked for $1 \mathrm{~h}$ at room temperature with $10 \%$ non-fat dry milk and subsequently incubated at $4^{\circ} \mathrm{C}$ overnight with anti-mouse antibody (1:300 dilution in blocking buffer). Once the membranes had been washed, they were incubated with a 1:1,000 dilution of horseradish peroxidase-conjugated anti-rabbit immunoglobulin G secondary antibody (ZSGB-Bio Co., Beijing, China) for $1 \mathrm{~h}$ at room temperature. The blots were visualized using an Enhanced Chemiluminescence kit (Pierce Biotechnology Inc., Rockford, IL, USA), and data were quantified using the Gel Doc EQ system (Bio-Rad, Hercules, CA, USA)

RNA extractions and quantitative polymerase chain reaction $(q P C R)$. Total cellular RNA was extracted with TRIzol ${ }^{\circledR}$ 
Table II. Effect of SEPS1 siRNA on the levels of ALT, AST and BUN ( $n=6)$.

\begin{tabular}{|c|c|c|c|c|c|c|}
\hline \multirow[b]{2}{*}{ Group } & \multicolumn{2}{|c|}{$\operatorname{ALT}(\mathrm{U} / \mathrm{l})$} & \multicolumn{2}{|c|}{ AST (U/l) } & \multicolumn{2}{|c|}{ BUN (mmol/l) } \\
\hline & $12 \mathrm{~h}$ & $24 \mathrm{~h}$ & $12 \mathrm{~h}$ & $24 \mathrm{~h}$ & $12 \mathrm{~h}$ & $24 \mathrm{~h}$ \\
\hline Sepsis & $66.7 \pm 15.2$ & $34.4 \pm 4.1$ & $19.7 \pm 3.2$ & $9.3 \pm 1.5$ & $182.2 \pm 23.7$ & $169.7 \pm 15.9$ \\
\hline Control & $71.3 \pm 14.6$ & $51.1 \pm 12.3$ & $21.2 \pm 1.9$ & $6.7 \pm 0.7$ & $258.5 \pm 78.2$ & $209.8 \pm 28.1$ \\
\hline SEPS1 siRNA & $77.8 \pm 22.1^{\mathrm{a}}$ & $53.5 \pm 7.3^{\mathrm{b}}$ & $20.0 \pm 5.7$ & $16.9 \pm 5.1^{\mathrm{a}, \mathrm{c}}$ & $264.8 \pm 89.3^{\mathrm{a}}$ & $261.0 \pm 73.4^{\mathrm{b}}$ \\
\hline
\end{tabular}

${ }^{\mathrm{a}} \mathrm{P}<0.05$, compared with sepsis group at the same time-point; ${ }^{\mathrm{b}} \mathrm{P}<0.01$, compared with sepsis group at the same time-point; ${ }^{\mathrm{c}} \mathrm{P}<0.05$, compared with control group at the same time-point. ALT, serum alanine transaminase; AST, aspartate aminotransferase; BUN, blood urea nitrogen; SEPS1, selenoprotein S; siRNA, small interfering RNA.

reagent (Takara, Seoul, Korea) according to the manufacturer's instructions. Reverse transcription was performed at $37^{\circ} \mathrm{C}$ for $1 \mathrm{~h}$ in a reaction mixture containing $2 \mathrm{mg}$ total RNA, $0.5 \mathrm{mg}$ oligo-dT primer, $10 \mathrm{mM}$ dNTPs, $25 \mathrm{U}$ RNase inhibitor and 200 U M-MLV reverse transcriptase (Promega). qPCR was performed using a SYBR FAST qPCR kit (KAPA, Boston, Massachusetts, USA) with $10 \mathrm{ng}$ cDNA according to the manufacturer's instructions. Cycling conditions were as follows: $95^{\circ} \mathrm{C}$ for $1.5 \mathrm{~min}$ and 40 subsequent cycles of $95^{\circ} \mathrm{C}$ for $3 \mathrm{sec}$, $56.4^{\circ} \mathrm{C}$ for $40 \mathrm{sec}$ and $72^{\circ} \mathrm{C}$ for $10 \mathrm{sec}$. Upon the completion of 40 PCR amplification cycles, melting curve analysis was performed. SEPS1 mRNA levels were normalized to actin, a stable housekeeping gene.

Immunohistochemical detection. Liver and lung tissue samples were deparaffinized three times with xylene for $5 \mathrm{~min}$ each, followed by rehydration with a series of absolute, $70 \%$ and $50 \%$ ethanol for three min each and washed under running tap water for $5 \mathrm{~min}$. Tissue samples were subsequently blocked with $3 \%$ hydrogen peroxide for $5 \mathrm{~min}$, placed in distilled water for $5 \mathrm{~min}$, followed by $10 \mathrm{~min}$ incubation with a 1:20 dilution of goat serum. Subsequently, tissue samples were incubated with anti-SEPS1 polyclonal serum at $4^{\circ} \mathrm{C}$ overnight and washed five times with phosphate-buffered saline and Tween 20 (PBST), for two min each. Tissue samples were then incubated with a 1:1,000 dilution of horseradish peroxidase-conjugated antibody (Sigma-Aldrich) for $30 \mathrm{~min}$ and washed again with PBST. Following washing, the samples were developed with 3,3'-diaminobenzidine substrate solution for $3 \mathrm{~min}$ and washed again with PBST. Finally, the tissue samples were counterstained with Harris' hematoxylin (Sigma-Aldrich) for $1 \mathrm{~min}$, followed by washing, differentiation with ethanol containing $1 \%$ acid alcohol solution, bluing with ammonia in water, another washing step, dehydration with increasing series of alcohols, clearance with xylene and subsequent mounting with dibutyl phthalate xylene (DPX).

Pathological examination. Processed liver and lung tissue samples were deparaffinized three times with xylene for two min each, rehydrated with a series of absolute, 95\% and $80 \%$ ethanol for two min each, followed by a wash with running tap water for $5 \mathrm{~min}$. Subsequently, the tissue samples were stained with Harris' haematoxylin (Sigma-Aldrich) for 5 min and washed with running tap water. Differentiation with $1 \%$ acid alcohol solution was performed for $10 \mathrm{sec}$, followed by

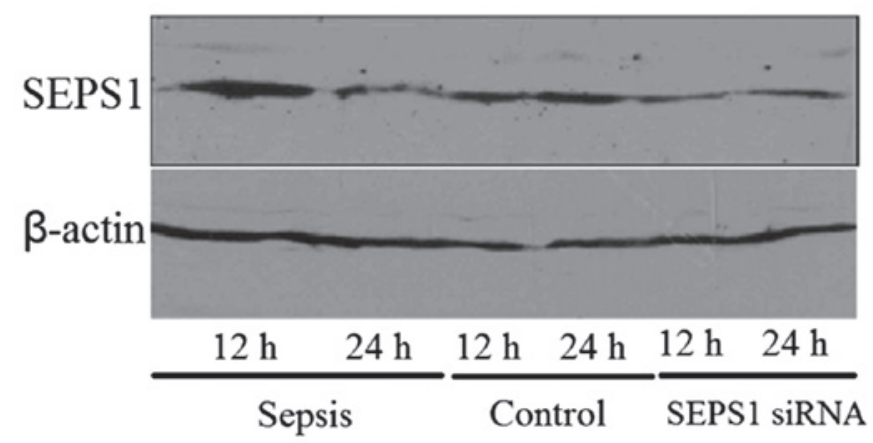

Figure 1. Effect of SEPS1 siRNA on SEPS1 protein expression in the liver. SEPS1, selenoprotein S; siRNA, small interfering RNA.

washing and bluing by placing the tissue samples into a solution of ammonia in water for $10 \mathrm{sec}$. Following a washing step, the samples were counterstained with eosin Y (Sigma-Aldrich) for two min, dehydrated with an increasing series of ethanol for two min each, cleared by three washes with xylene for two min each and finally mounted with DPX.

Statistical analysis. Values are expressed as the mean \pm standard deviation from a minimum of three independent experiments. The statistical significance of the results between each treated group was analyzed by Student's t-test. $\mathrm{P}<0.05$ was considered to indicate a statistically significant difference.

\section{Results}

Confirmation of SEPS1 silencing. In order to examine whether the SEPS1 gene was silenced, the expression of the SEPS1 gene was detected by qPCR and western blot analysis. SEPS1 protein expression in liver tissue decreased 12 and $24 \mathrm{~h}$ following transfection with SEPS1 siRNA (Fig. 1). The results of the immunohistochemical analysis also revealed that SEPS1 protein expression in liver and lung tissue decreased in the SEPS1 siRNA group (Figs. 2 and 3). qPCR results demonstrated that SEPS1 gene expression in liver tissue decreased significantly compared with the control group (Fig. 4).

SEPS1 silencing in mice with sepsis increases ALT, AST, $B U N, L D H, C K$ and $C K-M B$ levels. In the present study, important biochemical indicators were detected in order to reflect the effects on the liver, kidney and heart following 
Table III. Effect of SEPS1 siRNA on the levels of CK, LDH and CK-MB (n=5, U/1).

\begin{tabular}{|c|c|c|c|c|c|c|}
\hline \multirow[b]{2}{*}{ Group } & \multicolumn{2}{|c|}{ CK (U/l) } & \multicolumn{2}{|c|}{ LDH (U/l) } & \multicolumn{2}{|c|}{ CK-MB (U/1) } \\
\hline & $12 \mathrm{~h}$ & $24 \mathrm{~h}$ & $12 \mathrm{~h}$ & $24 \mathrm{~h}$ & $12 \mathrm{~h}$ & $24 \mathrm{~h}$ \\
\hline Sepsis & $2302.9 \pm 1378.4$ & $2118.4 \pm 923.5$ & $743.6 \pm 123.7$ & $604.8 \pm 114.7$ & $1848.5 \pm 1383.0$ & $1871.1 \pm 829.9$ \\
\hline Control & $1219.0 \pm 358.6$ & $1593.7 \pm 439.7$ & $535.2 \pm 52.4$ & $488.7 \pm 90.1$ & $1148.0 \pm 348.4$ & $1509.2 \pm 425.6$ \\
\hline SEPS1 siRNA & $2657.6 \pm 882.9^{\mathrm{b}}$ & $2349.2 \pm 127.4^{\mathrm{a}}$ & $725.7 \pm 186.3^{\mathrm{a}}$ & $584.7 \pm 114.7$ & $2602.2 \pm 856.6^{\mathrm{b}}$ & $2465.0 \pm 477.7^{b}$ \\
\hline
\end{tabular}

${ }^{a} \mathrm{P}<0.05$, compared with control group at the same time-point. ${ }^{\mathrm{b}} \mathrm{P}<0.01$, compared with control group at the same time-point. $\mathrm{CK}$, creatine kinase; LDH, lactic dehydrogenase; CK-MB, myocardial kinase; SEPS1, selenoprotein S; siRNA, small interfering RNA.
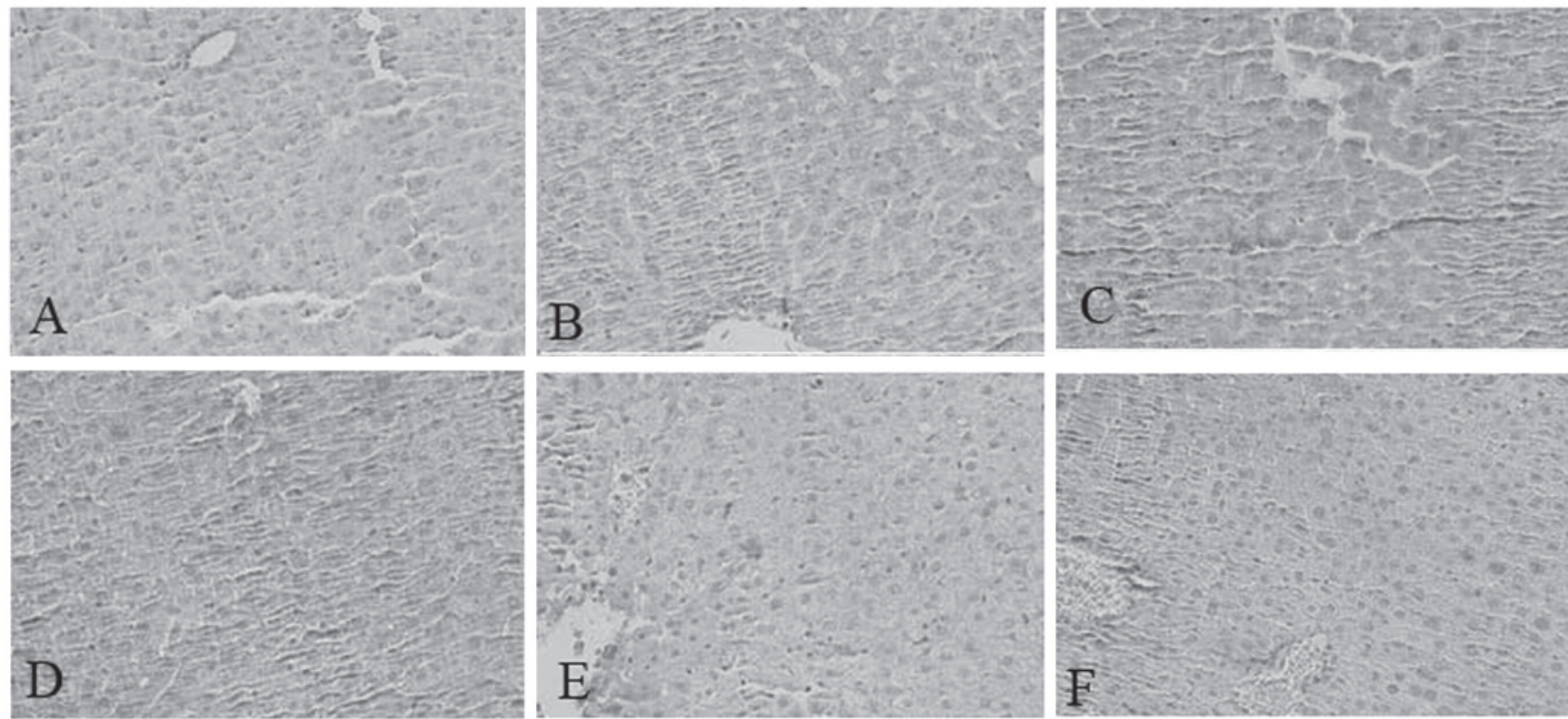

Figure 2. Effect of SEPS1 siRNA on SEPS1 protein expression in liver tissue assessed by immunohistochemistry. (A) Sepsis group at $12 \mathrm{~h}$; (B) sepsis group at $24 \mathrm{~h}$; (C) control group at $12 \mathrm{~h}$; (D) control group at $24 \mathrm{~h}$; (E) SEPS1 siRNA group at $12 \mathrm{~h}$ and (F) SEPS1 siRNA group at $24 \mathrm{~h}$. Magnification, x100. SEPS1, selenoprotein S; siRNA, small interfering RNA.
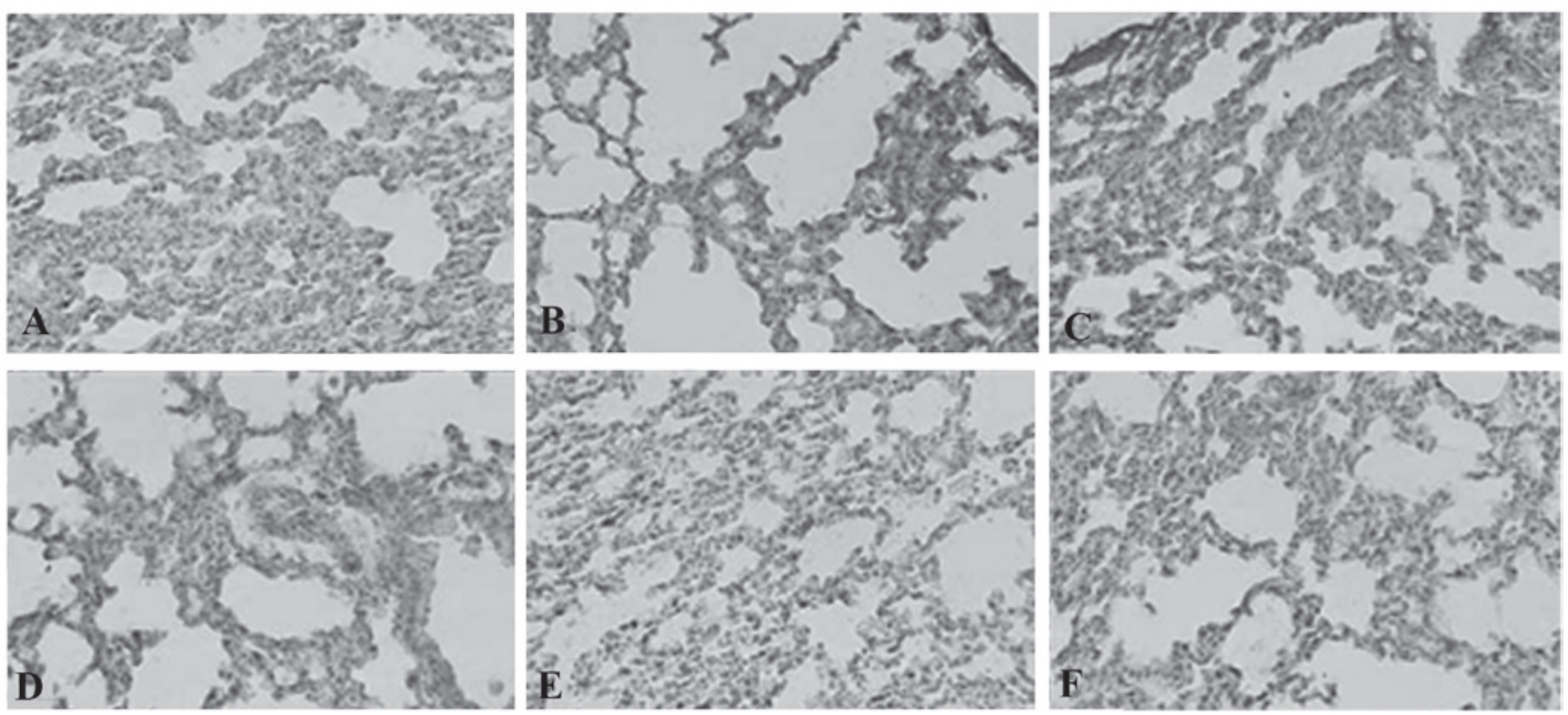

Figure 3. Effect of SEPS1 siRNA on SEPS1 protein expression in lung tissue assessed by immunohistochemistry. (A) Sepsis group at $12 \mathrm{~h}$; (B) sepsis group at $24 \mathrm{~h}$; (C) control group at $12 \mathrm{~h}$; (D) control group at $24 \mathrm{~h}$; (E) SEPS1 siRNA group at $12 \mathrm{~h}$ and (F) SEPS1 siRNA group at $24 \mathrm{~h}$. Magnification, x200. SEPS1, selenoprotein S; siRNA, small interfering RNA. 


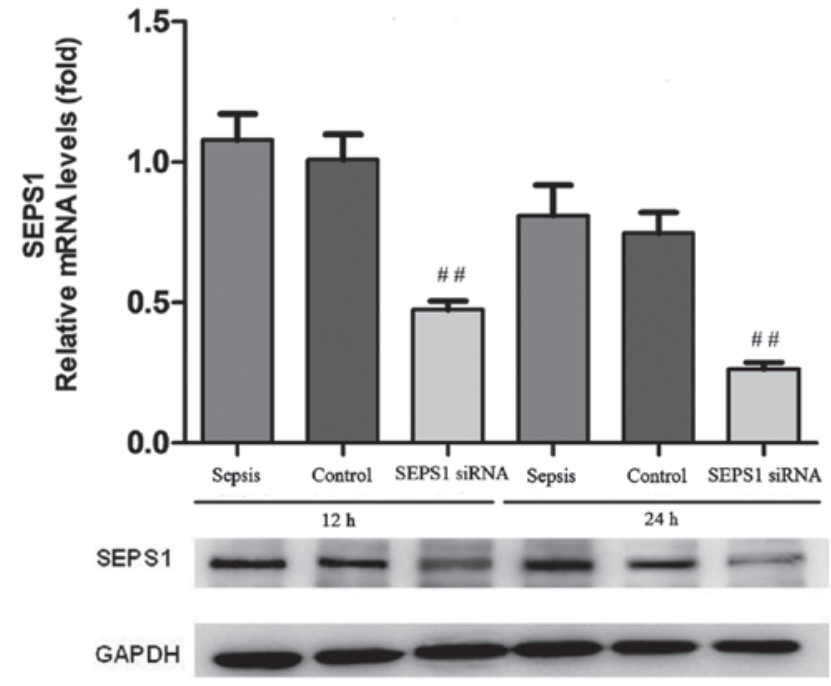

Figure 4. Effect of SEPS1 siRNA on SEPS1 gene expression in liver tissue Data present the means \pm standard error. ${ }^{\|} \mathrm{P}<0.05$; ${ }^{\# \prime} \mathrm{P}<0.01$ as compared with the control group. SEPS1, selenoprotein S; siRNA, small interfering RNA.

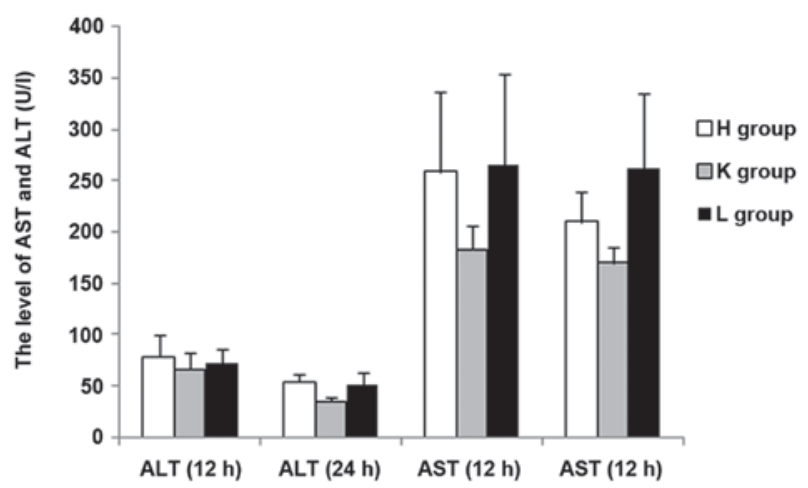

Figure 5. Levels of AST and ALT at $24 \mathrm{~h}$ compared with $12 \mathrm{~h}$ in the $\mathrm{H}, \mathrm{K}$ and $\mathrm{L}$ groups. $\mathrm{H}$ group, (LPS-induced sepsis group; $\mathrm{n}=10$ ): mice with intraperitoneal injection of LPS $(10 \mathrm{mg} / \mathrm{kg}$ ); K group, (scrambled siRNA group; $\mathrm{n}=10$ ): Mice transfected with scrambled control siRNA $12 \mathrm{~h}$ prior to injection with LPS; L group, (SEPS1 siRNA group; $\mathrm{n}=10$ ): Mice transfected with SEPS1 siRNA $12 \mathrm{~h}$ prior to injection with LPS. ALT, serum alanine transaminase AST, aspartate aminotransferase; LPS, lipopolysaccharide; SEPS1, selenoprotein S; siRNA, small interfering RNA.

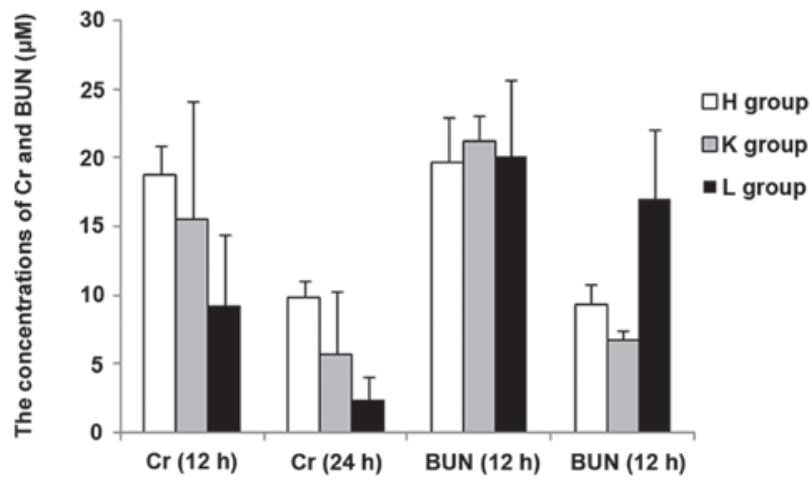

Figure 6. The level of $\mathrm{Cr}$ and BUN at $24 \mathrm{~h}$ compared with $12 \mathrm{~h}$ in the $\mathrm{H}, \mathrm{K}$ and $\mathrm{L}$ groups. $\mathrm{H}$ group, (LPS-induced sepsis group; $\mathrm{n}=10$ ): Mice with intraperitoneal injection of LPS (10 mg/kg); K group, (scrambled siRNA group; $\mathrm{n}=10$ ): Mice transfected with scrambled control siRNA $12 \mathrm{~h}$ prior to injection with LPS; L group, (SEPS1 siRNA group; $n=10$ ): Mice transfected with SEPS1 siRNA $12 \mathrm{~h}$ prior to injection with LPS. Cr, creatinine; LPS, lipopolysaccharide; BUN, blood urea nitrogen; SEPS1, selenoprotein S; siRNA, small interfering RNA.
siRNA silencing of the SEPS1 gene. At $12 \mathrm{~h}$ following injection with LPS, the concentrations of ALT and BUN exhibited no statistical difference among the three groups $(\mathrm{P}>0.05)$; AST and LDH levels exhibited significant differences between the groups except for a non-statistical difference between the $\mathrm{H}$ and $\mathrm{L}$ groups $(\mathrm{P}>0.05)$; the $\mathrm{Cr}$ levels showed no statistical difference among the groups except for a significant difference between the $\mathrm{H}$ and $\mathrm{L}$ groups $(\mathrm{P}<0.05)$; $\mathrm{CK}$ and $\mathrm{CK}-\mathrm{MB}$ concentrations exhibited no statistical difference among the groups except for a significant difference between the $\mathrm{K}$ and $\mathrm{L}$ groups $(\mathrm{P}<0.05)$. At $24 \mathrm{~h}$ following injection with LPS, the concentration of ALT was significantly higher in the H group than in the other two groups $(\mathrm{P}<0.05)$, and demonstrated no statistical difference between the $\mathrm{K}$ and $\mathrm{L}$ groups; there were significant differences among the three groups in the concentrations of AST and BUN $(\mathrm{P}<0.05)$; there was no significant difference among the three groups in $\mathrm{LDH}$ levels $(\mathrm{P}>0.05)$; the statistical results of difference in $\mathrm{Cr}, \mathrm{CK}$ and $\mathrm{CK}-\mathrm{MB}$ concentrations among the three groups at $24 \mathrm{~h}$ were the same as that at $12 \mathrm{~h}$. There was a significant increase in the ALT levels and a significant decrease in the $\mathrm{Cr}$ levels at $24 \mathrm{~h}$ compared with $12 \mathrm{~h}$ among the groups $(\mathrm{P}<0.05)$. Furthermore, there was a significant increase in the AST levels and a significant decrease in the BUN levels at $24 \mathrm{~h}$ compared with $12 \mathrm{~h}$ in the $\mathrm{H}$ and $\mathrm{K}$ groups $(\mathrm{P}<0.05)$; however, the difference in group $\mathrm{L}$ was not significant. There was no significant difference in $\mathrm{CK}, \mathrm{LDH}$ and $\mathrm{CK}-\mathrm{MB}$ concentrations at $24 \mathrm{~h}$ compared with $12 \mathrm{~h}$ among the groups $(\mathrm{P}<0.05)$ (Figs. 5, 6 and 7). The results demonstrated that the blood levels of ALT, AST, BUN, CK-MB, CK and LDH all increased in the SEPS1 siRNA group following silencing of the SEPS1 gene with SEPS1 siRNA (Tables II and III).

SEPS1 silencing in mice with sepsis increases TNF- $\alpha$ and IL-6 levels. To investigate the proinflammatory cytokine levels in mice with sepsis, the effect of SEPS1 siRNA on the circulating levels of primary (TNF- $\alpha$ ) and secondary (IL-6) cytokines was examined. At $12 \mathrm{~h}$ following LPS injection, IL-6 and TNF- $\alpha$ levels were highest in group K and lowest in group H. However, neither IL-6 nor TNF- $\alpha$ levels exhibited a statistical difference among the three groups $(\mathrm{P}>0.05)$. At $24 \mathrm{~h}$, following LPS injection, IL- 6 and TNF- $\alpha$ levels were highest in group $\mathrm{L}$ and lowest in group $\mathrm{K}$. There was a significant difference in IL-6 levels between all groups except for the difference between groups $\mathrm{H}$ and $\mathrm{K}$, whereas no significant difference in $\mathrm{TNF}-\alpha$ levels was present between the groups except for a statistically significant difference between groups $\mathrm{K}$ and $\mathrm{L}$. There was a significant decrease in the IL-6 and TNF- $\alpha$ levels at $24 \mathrm{~h}$ compared with $12 \mathrm{~h}$ in the $\mathrm{K}$ group $(\mathrm{P}<0.05)$. However, there was no significant difference in IL- 6 and TNF- $\alpha$ levels at $24 \mathrm{~h}$ compared with $12 \mathrm{~h}$ in the other groups $(\mathrm{P}>0.05)$ (Fig. 8).

SEPS1 silencing in mice with sepsis increases p38 MAPK phosphorylation. MAPKs are involved in signal transduction pathways leading to the regulation of inflammatory mediators. In the present study, the SEPS1 siRNA group enhanced p-p38 protein levels at 12 and $24 \mathrm{~h}$ following LPS stimulation (Fig. 9), suggesting that SEPS1 siRNA treatment activated the phosphorylation of p38 MAPK. 


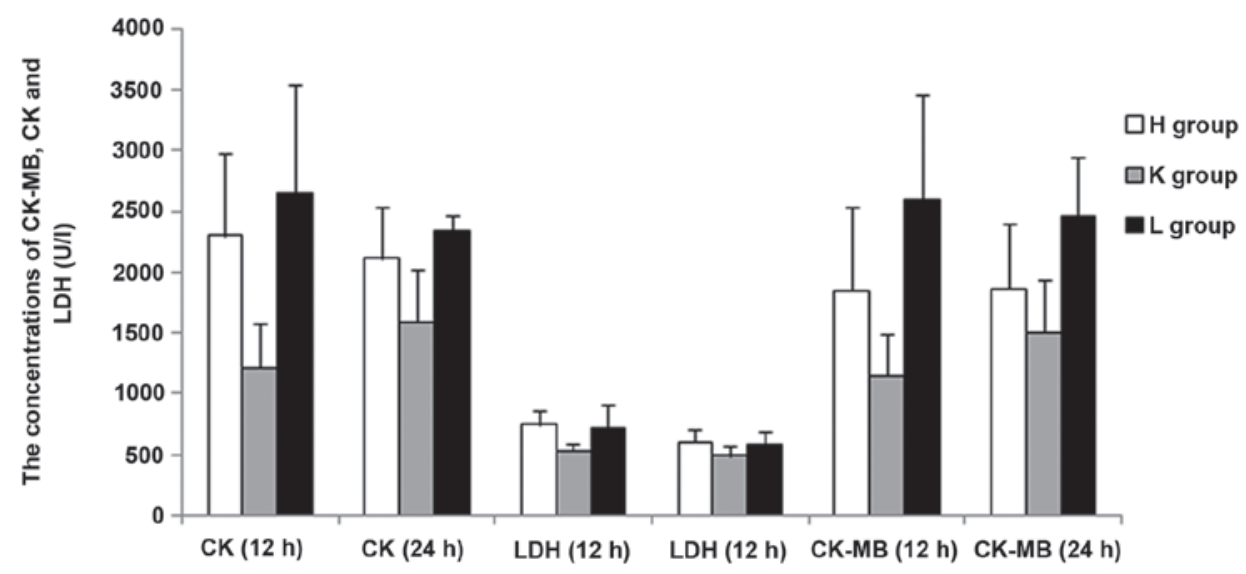

Figure 7. The level of CK-MB, CK and LDH at $24 \mathrm{~h}$ compared with $12 \mathrm{~h}$ in the H, K and L groups. H group, (LPS-induced sepsis group; $\mathrm{n}=10$ ): Mice with intraperitoneal injection of LPS (10 mg/kg); K group, (scrambled siRNA group; $\mathrm{n}=10)$ : Mice transfected with scrambled control siRNA $12 \mathrm{~h}$ prior to injection with LPS; L group, (SEPS1 siRNA group; $\mathrm{n}=10$ ): Mice transfected with SEPS1 siRNA $12 \mathrm{~h}$ prior to injection with LPS; CK-MB, myocardial kinase; Cr, creatinine; LDH, lactic dehydrogenase; SEPS1, selenoprotein S; siRNA, small interfering RNA.

Sepsis in SEPS1-silenced mice causes tissue damage. Pathological results demonstrated that the liver and lung cells swelled significantly and the inflammatory cells infiltrated the portal area, indicating that cell lesion markedly occurred in the SEPS1 siRNA group compared with the control group, which may correlate with the decrease in SEPS1 gene expression (Figs. 10 and 11).

\section{Discussion}

SEPS1 is a newly identified member of the selenoprotein family that contains enzymes, including thioredoxin reductase and glutathione peroxidase (13). The human gene SEPS1 is located on chromosome $15 \mathrm{q} 26.3$, consists of six exons and encodes a 189-amino acid protein. This region of chromosome 15 was previously suggested to contain quantitative trait loci that influence inflammatory disorders, including insulin-dependent diabetes mellitus, Alzheimer's disease and celiac disease (14-17). It has been observed that genetic variation in the SEPS1 gene correlated strongly with circulating levels of pro-inflammatory cytokines in human populations and that SEPS1 may regulate cytokine production in cultured macrophage cells $(11,18)$. It has also been reported that cytokines have a direct impact on SEPS1 levels (19). Thus, there appears to be a regulatory loop whereby cytokines stimulate the expression of SEPS1, which in turn suppresses cytokine production. In order to clarify the importance of SEPS1 in multiple organ dysfunction in mice with sepsis, siRNA was used to inhibit SEPS1 gene expression and observe the impact on organ function and prognosis.

RNA interference (RNAi) is an RNA-dependent gene silencing process controlled by the RNA-induced silencing complex (RISC) and is initiated by short double-stranded RNA molecules in the cell cytoplasm, where they interact with the catalytic RISC component, argonaute. RNAi is widely used in the study of gene function and biological genetic improvement. Synthetic double-stranded (ds) siRNA in mammalian cells exerted a target gene-silencing effect. siRNA is favored as a gene therapy drug due to its specific efficiency in addition to its enormous potential. Although it
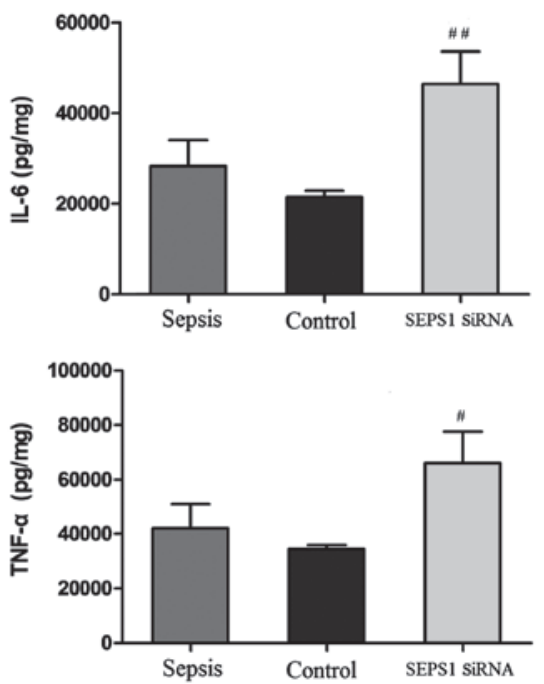

Figure 8. The effect of SEPS1 siRNA on circulating levels of IL-6 and TNF- $\alpha$. Data present the mean \pm standard error. ${ }^{\#} \mathrm{P}<0.05 ;{ }^{\# \#} \mathrm{P}<0.01$ compared with the control group. TNF- $\alpha$, tumor necrosis factor- $\alpha$; IL-6, interleukin-6; SEPS1, selenoprotein S; siRNA, small interfering RNA.

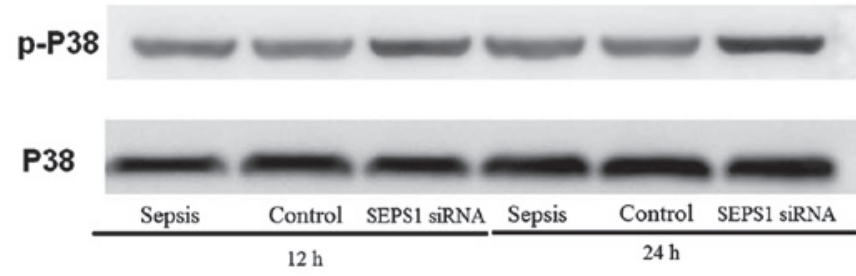

Figure 9. The effect of SEPS1 siRNA on the phosphorylation of p38 MAPK in liver tissue. SEPS1, selenoprotein S; p38 MAPK, p38 mitogen-activated protein kinases; siRNA, small interfering RNA.

is difficult to introduce long dsRNA strands into mammalian cells due to the interferon response, the use of siRNA mimics has been more successful (20). In the present study, siRNAs for SEPS1 and a scrambled control were synthesized. In order to examine whether the SEPS1 gene was silenced, SEPS1 gene and protein expression were assessed. The 

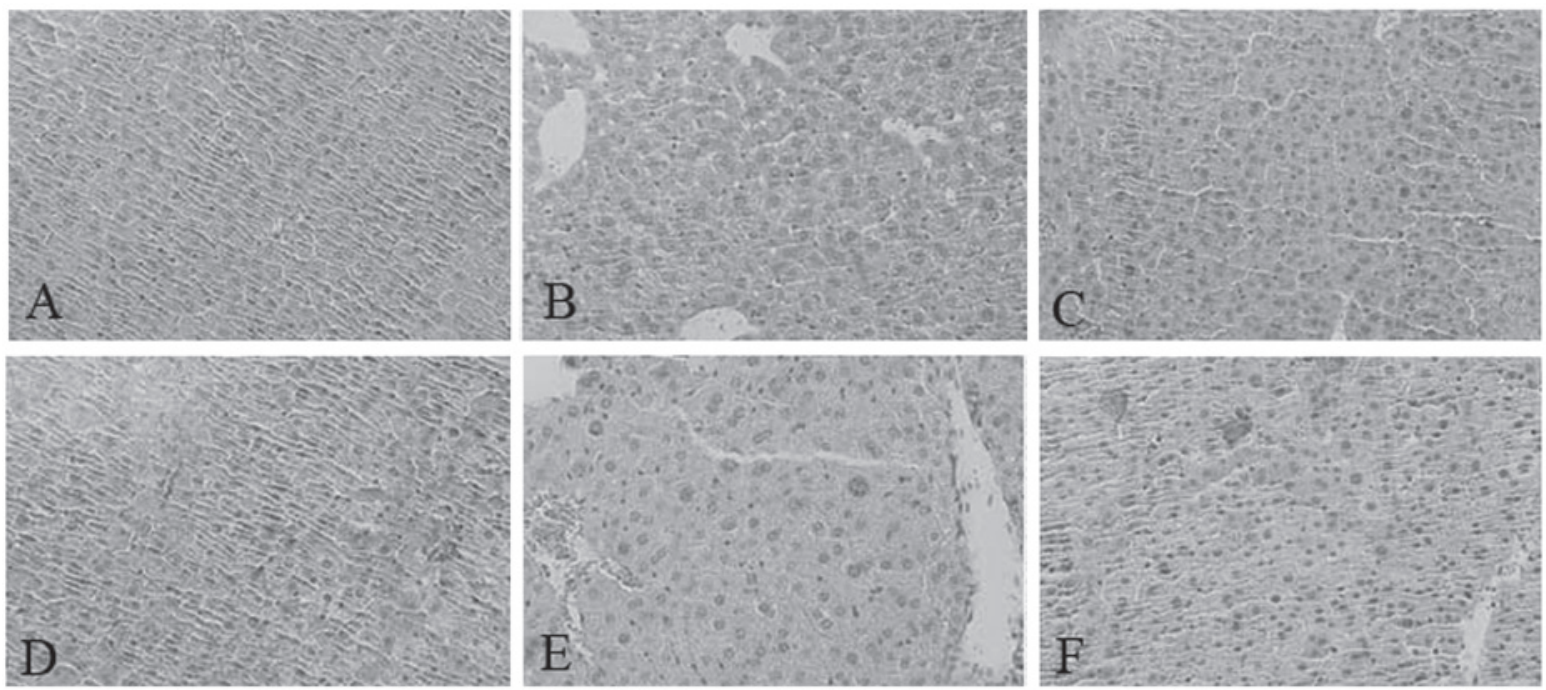

Figure 10. Damaging effect of SEPS1 on liver tissue according to pathological observations. (A) Sepsis group at $12 \mathrm{~h}$; (B) sepsis group at $24 \mathrm{~h}$; (C) control group at $12 \mathrm{~h}$; (D) control group at $24 \mathrm{~h}$; (E) SEPS1 siRNA group at $12 \mathrm{~h}$ and (F) SEPS1 siRNA group at $24 \mathrm{~h}$. Magnification, x100. SEPS1, selenoprotein 1; siRNA, small interfering RNA.
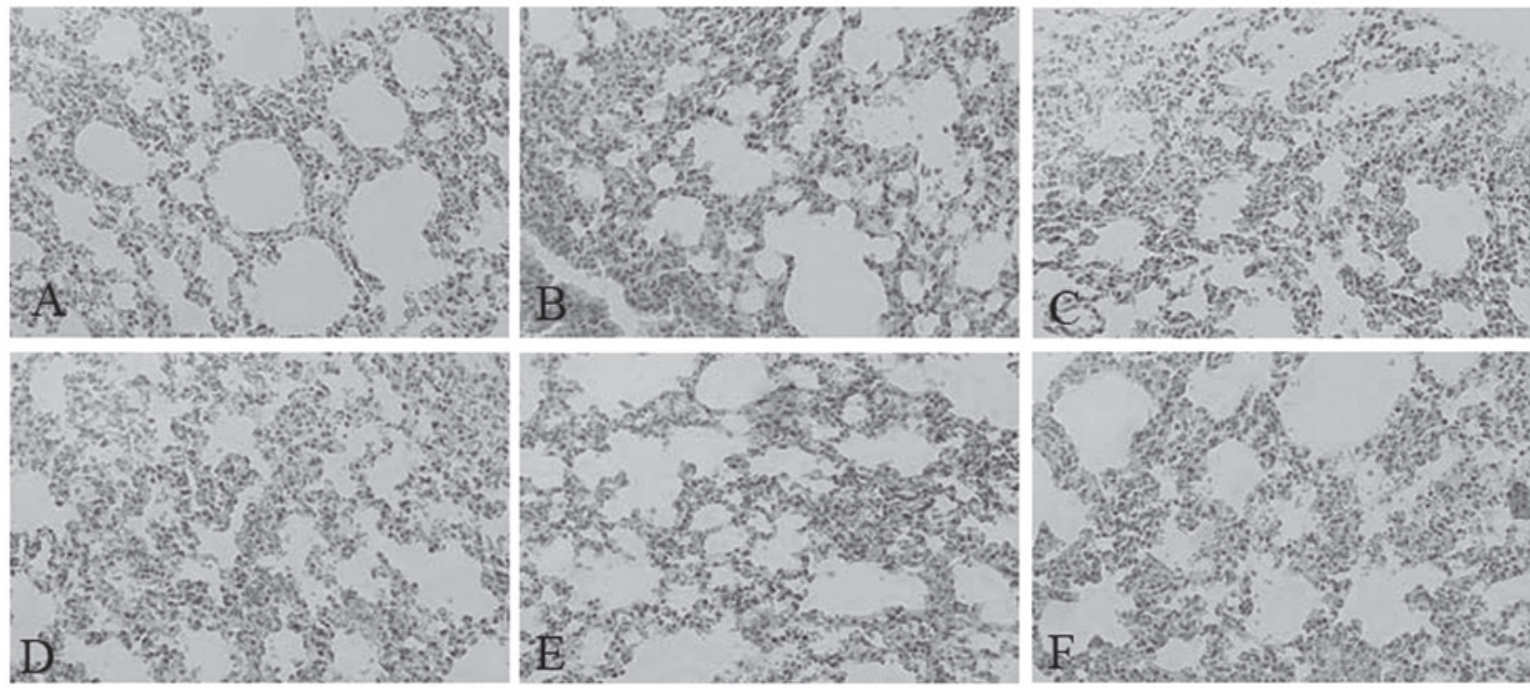

Figure 11. Damaging effect of SEPS1 on lung tissue according to pathological observations. (A) Sepsis group at $12 \mathrm{~h}$; (B) sepsis group at $24 \mathrm{~h}$; (C) control group at $12 \mathrm{~h}$; (D) control group at $24 \mathrm{~h}$; (E) SEPS1 siRNA group at $12 \mathrm{~h}$ and (F) SEPS1 siRNA group at $24 \mathrm{~h}$. Magnification, x200. SEPS1, selenoprotein S; siRNA, small interfering RNA.

results demonstrated that SEPS1 protein expression in liver tissue decreased 12 and $24 \mathrm{~h}$ following injection with SEPS1 siRNA. SEPS1 gene expression in liver tissue also decreased significantly. These results demonstrated that the SEPS1 gene was silenced.

Sepsis is defined as a systemic inflammatory response to a microbial infection that results from excessive stimulation of the host immune system by pathogen components, producing various proinflammatory cytokines. The overproduction of these cytokines then causes systemic inflammation that may lead to the lethal multiple organ damage (21). In the present study, the influence of important organ function and prognosis in mice with sepsis was investigated following silencing of the SEPS1 gene with SEPS1 siRNA. Several biochemical parameters were selected in order to reflect the important organ condition. The results demonstrated that the levels of
ALT, AST, BUN, CK-MB, CK and LDH all increased in the SEPS1 siRNA group following SEPS1 siRNA silencing of the SEPS1 gene, indicating that damage to the liver, kidney and heart was aggravated. Thus, SEPS1 has an important role in protecting the liver, kidney and heart from damage due to sepsis.

In order to investigate the protective role of SEPS1 in mice with sepsis, the effect of SEPS1 siRNA on circulating levels of primary (TNF- $\alpha$ ) and secondary (IL-6) proinflammatory cytokines was assessed as an index of inflammation (22-24). The TNF- $\alpha$ and IL- 6 levels in the SEPS1 siRNA group significantly increased compared with the control group. SEPS1 siRNA increased the levels of TNF- $\alpha$ in liver tissue and may have subsequently aggravated liver dysfunction.

The MAPK signaling pathways consist of a series of kinases that are sequentially activated and consequently phosphorylate 
the downstream kinases and transduce extracellular stimuli into intracellular responses. The MAPK family includes extracellular signal-regulated kinases, c-Jun N-terminal kinases and p38 MAPK. One of the major functions of MAPK is the activation of transcription factors, several of which bind to the promoters of pro-inflammatory cytokines $(25,26)$. Furthermore, the MAPKs have been previously implicated in the signaling pathways relevant to LPS-induced inflammation. LPS activates all three MAPK type kinases in mouse macrophages (27). p38 is activated by LPS stimulation and has been theorized to have an important function in the control of IL- 6 and TNF- $\alpha$ gene expression. Numerous downstream targets of the p38 MAPK pathway are transcription factors which regulate transcription of proinflammatory mediators. In the present study, the SEPS1 siRNA group enhanced the phospho-p38 expression at 12 and $24 \mathrm{~h}$ following LPS stimulation, suggesting that SEPS1 siRNA treatment increased the phosphorylation of p38 MAPK. From this it may be inferred that an increase in the levels of proinflammatory cytokines is due to the activation of the p38 MAPK pathway.

The pathological results demonstrated that liver and lung cell lesions markedly occurred in the SEPS1 siRNA group as compared with the control group, which may correlate with the decrease in SEPS1 gene expression. Therefore, it may be inferred that the SEPS1 gene exhibited a protective effect on the livers and lungs of mice with sepsis.

These data suggest that SEPS1 may have an important role in regulating processes associated with sepsis, particularly in protecting important organs from damage and decreasing the production of inflammatory cytokines. Increasing SEPS1 gene expression may be a new way to reduce sepsis, liver and other organ damage.

\section{Acknowledgements}

This study was supported by grants from the National Natural Science Foundation of China (no. 30972523) and the Foundation of the 'Twelfth Five-Year Plan' for Medical Science Development of the People's Liberation Army (nos BWS11J048 and CWS11J109).

\section{References}

1. Harrison C: Sepsis: calming the cytokine storm. Nat Rev Drug Discov 9: 360-361, 2010.

2. Delsesto D and Opal SM: Future perspectives on regulating pro-and anti-inflammatory responses in sepsis. Contrib Microbiol 17: 137-156, 2011.

3. Shubin NJ, Monaghan SF and Ayala A: Anti-inflammatory mechanisms of sepsis. Contrib Microbiol 17: 108-124, 2011.

4. Lewis DH, Chan DL, Pinheiro D, Armitage-Chan E and Garden OA: The immunopathology of sepsis: pathogen recognition, systemic inflammation, the compensatory anti-inflammatory response, and regulatory $\mathrm{T}$ cells. J Vet Intern Med 26: 457-482, 2012.

5. Lorente JA, Delgado MA and Landin L: Septic shock and nitric oxide. Enferm Infecc Microbiol Clin 15: 14-19, 1997 (In Spanish)
6. Lvovschi V, Arnaud L, Parizot C, et al: Cytokine profiles in sepsis have limited relevance for stratifying patients in the emergency department: a prospective observational study. PLoS One 6: e28870, 2011.

7. AndoH,TakamuraT,OtaT,Nagai Y and Kobayashi K: Cerivastatin improves survival of mice with lipopolysaccharide-induced sepsis. J Pharmacol Exp Ther 294: 1043-1046, 2000.

8. Ye Y, Shibata Y, Yun C, Ron D and Rapoport TA: A membrane protein complex mediates retro-translocation from the ER lumen into the cytosol. Nature 429: 841-847, 2004.

9. Ye Y, Shibata Y, Kikkert M, van Voorden S, Wiertz E and Rapoport TA: Recruitment of the p97 ATPase and ubiquitin ligases to the site of retrotranslocation at the endoplasmic reticulum membrane. Proc Natl Acad Sci USA 102: 14132-14138, 2005.

10. Hart K, Landvik NE, Lind H, Skaug V, Haugen A and Zienolddiny S: A combination of functional polymorphisms in the CASP8, MMP1, IL10 and SEPS1 genes affects risk of non-small cell lung cancer. Lung Cancer 71: 123-129, 2011.

11. Curran JE, Jowett JB, Elliott KS, et al: Genetic variation in selenoprotein $S$ influences inflammatory response. Nat Genet 37: 1234-1241, 2005.

12. Rayman MP: Selenoproteins and human health: insights from epidemiological data. Biochim Biophys Acta 1790: 1533-1540, 2009.

13. Kryukov GV, Castellano S, Novoselov SV, et al: Characterization of mammalian selenoproteomes. Science 300: 1439-1443, 2003.

14. Blacker D, Bertram L, Saunders AJ, et al: Results of a high-resolution genome screen of 437 Alzheimer's disease families. Hum Mol Genet 12: 23-32, 2003.

15. Field LL, Tobias R and Magnus T: A locus on chromosome $15 q 26$ (IDDM3) produces susceptibility to insulin-dependent diabetes mellitus. Nat Genet 8: 189-194, 1994.

16. Zamani M, Pociot F, Raeymaekers P, Nerup J and Cassiman JJ: Linkage of type I diabetes to 15q26 (IDDM3) in the Danish population. Hum Genet 98: 491-496, 1996.

17. Susi M, Holopainen P, Mustalahti K, Maki M and Partanen J: Candidate gene region $15 \mathrm{q} 26$ and genetic susceptibility to coeliac disease in Finnish families. Scand J Gastroenterol 36: 372-374, 2001.

18. Fradejas N, Pastor MD, Mora-Lee S, Tranque P and Calvo S: SEPS1 gene is activated during astrocyte ischemia and shows prominent antiapoptotic effects. J Mol Neurosci 35: 259-265, 2008.

19. Gao Y, Hannan NR, Wanyonyi S, et al: Activation of the selenoprotein SEPS1 gene expression by pro-inflammatory cytokines in HepG2 cells. Cytokine 33: 246-251, 2006.

20. Paddison PJ, Caudy AA and Hannon GJ: Stable suppression of gene expression by RNAi in mammalian cells. Proc Natl Acad Sci USA 99: 1443-1448, 2002.

21. Oberholzer A, Oberholzer C and Moldawer LL: Sepsis syndromes: understanding the role of innate and acquired immunity. Shock 16: 83-96, 2001.

22. Saadeddin SM, Habbab MA and Ferns GA: Markers of inflammation and coronary artery disease. Med Sci Monit 8: RA5-RA12, 2002.

23. Bickel C, Rupprecht HJ, Blankenberg S, et al: Relation of markers of inflammation (C-reactive protein, fibrinogen, von Willebrand factor, and leukocyte count) and statin therapy to long-term mortality in patients with angiographically proven coronary artery disease. Am J Cardiol 89: 901-908, 2002.

24. de Maat MP and Kluft C: The association between inflammation markers, coronary artery disease and smoking. Vascul Pharmacol 39: 137-139, 2002.

25. Lin YT, Chen YH, Yang YH, et al: Heme oxygenase-1 suppresses the infiltration of neutrophils in rat liver during sepsis through inactivation of p38 MAPK. Shock 34: 615-621, 2010.

26. Qian F, Deng J, Gantner BN, et al: Map kinase phosphatase 5 protects against sepsis-induced acute lung injury. Am J Physiol Lung Cell Mol Physiol 302: L866-L874, 2012.

27. Ruland $J$ and Mak TW: Transducing signals from antigen receptors to nuclear factor kappaB. Immunol Rev 193: 93-100, 2003. 